\title{
Polifasia cognitiva nas representações sociais do alcoolismo
}

\author{
Cognitive polyphasia in the social representations of alcoholism
}

\author{
Luiz Gustavo Silva Souza ${ }^{1}$ \\ Maria Cristina Smith Menandro ${ }^{2}$ \\ Paulo Rogério Meira Menandro ${ }^{3}$
}

\begin{abstract}
RESUMO: Diferentes racionalidades agem na construção de representações sociais, por meio do processo de polifasia cognitiva. Parte-se da hipótese de que profissionais de saúde não se restringem ao saber técnico-científico ao construir suas representações. Esta pesquisa teve o objetivo de compreender as representações sociais do alcoolismo construídas por profissionais de Saúde da Família, em especial a dimensão da polifasia cognitiva. Participaram 40 profissionais, recrutados igualmente quanto a gênero e profissão (médicos e não-médicos). Eles responderam a entrevistas semiestruturadas e os dados foram analisados com Classificação Hierárquica Descendente com auxílio do software ALCESTE. Os resultados mostram que o alcoolismo foi representado simultaneamente como 1 ) doença multifatorial a ser tratada de forma integral: as causas são conhecidas e a equipe de saúde deve adotar procedimentos técnicos multiprofissionais; e 2) como problema social, relacionado à pobreza das comunidades, a ser tratado com os (poucos) recursos disponíveis e com força de vontade: as causas são obscuras, o alcoolista não recebe cuidados, há motivações contraditórias entre usuários e profissionais, o tratamento depende da força de vontade e de recursos alheios. Discute-se a presença de crenças que associam o alcoolismo à pobreza. Os profissionais recorreram implicitamente aos universos reificado e consensual para a construção das representações sociais, caracterizando a incidência da polifasia cognitiva. São realizadas sugestões metodológicas para uso do ALCESTE: um quadro para interpretação das Classes de trechos de discurso geradas com auxílio do software e o uso dos conceitos de universo reificado e universo consensual para interpretação de seus gráficos (dendrogramas).
\end{abstract}

Palavras-chave: representação social; alcoolismo; atenção primária à saúde; polifasia cognitiva; ALCESTE.

ABSTRACT: Different rationalities participate in the construction of social representations through the process of cognitive polyphasia. We considered the hypothesis that health professionals do not use only technical-scientific knowledge to construct their representations. This research aimed at understanding the social representations of alcoholism constructed by Brazilian Family Health professionals, especially the dimension of cognitive polyphasia. Forty health professionals equally sampled by gender and profession (physicians and non-physicians) participated in this research. They answered to semi-structured interviews. We analyzed the data with the Top-down Hierarchical Classification implemented in the software ALCESTE. Results show that professionals simultaneously represented alcoholism as: 1) a multifactorial disease to be treated with a comprehensive approach, its causes are known, the health team must apply multi-professional procedures. 2) A social problem related to the poverty of communities, to be treated with the (few) available resources and with willpower. Its causes are obscure, the alcoholic patient does not receive health care, there are contradictory motivations between patients and professionals and treatment depends on willpower and non-available resources. We discuss the possible influence of cultural beliefs that associate alcoholism to poverty.

\footnotetext{
${ }^{1}$ Doutor em Psicologia; Professor do Departamento de Psicologia (CPS) da Universidade Federal Fluminense - Campos dos Goytacazes, RJ, Brasil. E-mail: luizsouza@hotmail.com.

2 Doutora em Psicologia; Professora do Programa de Pós-Graduação em Psicologia da Universidade Federal do Espírito Santo - Vitória, ES, Brasil.

${ }^{3}$ Doutor em Psicologia; Professor do Programa de Pós-Graduação em Psicologia da Universidade Federal do Espírito Santo Vitória, ES, Brasil.
} 
Professionals implicitly considered the reified universe and the consensual universe to construct their social representations, what characterizes the influence of cognitive polyphasia. We make methodological suggestions regarding the use of the software ALCESTE: a chart for the interpretation of Classes of simple statements generated by the software and the use of the concepts of reified universe and consensual universe for the interpretation of its graphics (dendrograms).

Keywords: social representation; alcoholism; primary health care; cognitive polyphasia; ALCESTE.

\section{Introdução}

A pesquisa relatada neste artigo teve o objetivo de compreender as representações sociais do alcoolismo construídas por profissionais brasileiros de Saúde da Família e, especialmente, a dimensão da "polifasia cognitiva" (Moscovici, 1961) na construção dessas representações. $O$ artigo faz também proposições metodológicas para uso do software ALCESTE, desenvolvido por Reinert (2000): um quadro para facilitar a nomeação das Classes geradas com auxílio do software (Anexo 1) e uma forma de interpretação dos resultados baseada nos conceitos de "universo reificado" e de "universo consensual" (Moscovici, 2007). Com isso, apresenta-se uma proposta de articulação teórico-metodológica entre o ALCESTE e a Teoria das Representações Sociais.

Há algumas décadas, em todo o mundo, a Atenção Primária à Saúde (APS) é concebida como nível estratégico de atenção à saúde, tendo em vista sua capacidade singular de agir sobre os modos de vida das populações atendidas. Caracteriza-se pela proximidade, tanto geográfica quanto afetiva, entre profissionais e usuários e pelo caráter longitudinal do atendimento (World Health Organization, 2008).

No Brasil, a Estratégia Saúde da Família foi proposta como conjunto de princípios e ações próprios da APS para orientar todo o sistema de saúde. A assistência deve deixar de enfocar a cura de doenças, característica do persistente modelo biomédico tradicional, em favor de abordagens centradas na promoção de saúde e transformação de estilos de vida (Viana \& Dal Poz, 1998). Esses objetivos são particularmente importantes para o cuidado dirigido a problemas com o álcool e a condições crônicas como o alcoolismo (Brasil, 2004; Kanno, Bellodi \& Tess, 2012; Souza, 2012).

Na produção científica contemporânea sobre o alcoolismo, a etiologia é descrita como gradual e multifatorial, incluindo fatores genéticos, sociais e psicológicos (Rotgers \& Davis, 2006; Souza \& Noto, 2013). Intervenções breves e aconselhamento são indicados, em APS, para diminuir riscos associados ao consumo, para promover a motivação, a mudança de comportamentos ou, dependendo do caso, a adoção de tratamentos mais intensivos em centros especializados. Para o dependente de álcool, indica-se desintoxicação com manejo de síndrome de abstinência e complicações associadas. São utilizados recursos medicamentosos e (psico) terapêuticos. Intervenções buscam construir ou fortalecer redes sociais. Relações de parceria podem ser estabelecidas entre profissionais de saúde e grupos de mútua ajuda como os Alcoólicos Anônimos. O conjunto de atores e serviços a ser envolvido em atividades de promoção de saúde, prevenção, tratamento e reabilitação psicossocial é potencialmente grande (Heather \& Stockwell, 2004).

Entretanto, o alcoolismo foi, ao longo da história, alvo de persistente condenação moral, inclusive por parte de pesquisadores e profissionais das ciências médicas e da saúde (Sournia, 1986; Ronzani \& Furtado, 2010) e foi tradicionalmente associado à pobreza e a teses sobre a degenerescência, crenças sobre a degradação física e moral das classes populares (Sournia, 1986; Matos, 2000). 
O alcoolismo é construído socialmente como desvio, ou seja, como uma afronta aos padrões morais e aos valores da sociedade que o (re) produz (Conrad \& Schneider, 1992). Para o senso comum, explicações científicas do alcoolismo (genéticas, psicológicas, sociais) parecem menos convincentes que a imagem concreta da "queda" do alcoolista, de sua (auto) segregação e degeneração moral e social. A percepção social do alcoolista não recorre necessariamente à quantidade de álcool ingerida, nem a critérios descritos em manuais médicos. O alcoolista é identificado quando seu consumo de álcool é associado à degradação de papéis sociais. Para identificar o alcoolista, destaca-se a percepção de seu descontrole, da vontade, da fala, do comportamento, e de seu isolamento social, solidão e quebra de protocolos (Ancel \& Gaussot, 1998; Souza, 2012).

Dentre os conhecimentos científicos e aqueles produzidos pelo senso comum sobre o alcoolismo, que elementos adotam os profissionais de APS, especialmente de Saúde da Família, para construir a realidade objetiva-subjetiva do fenômeno? Essa questão, que norteou a presente pesquisa, é relevante, tendo em vista o importante papel atribuído à APS pelas políticas públicas dirigidas a usuários de álcool e outras drogas (Brasil, 2004).

\section{Fundamentação teórica}

Representações sociais são teorias de senso comum, elaboradas por sujeitos e grupos sociais acerca de um objeto, que integram saberes de diferentes ordens, conhecimentos científicos, crenças e imagens, além de padrões afetivo-avaliativos, e que contribuem para definir o objeto, para construir sua realidade, para aferir seu valor e para prescrever e justificar comportamentos em relação a ele (Moscovici, 1961, 2007).

Nas sociedades industrializadas, marcadas pela presença das ciências, as representações sociais integram conhecimentos científicos e outros tipos de saberes eruditos. Entretanto, não se restringem a esses saberes. Elas possuem caráter inventivo, capaz de recriar saberes especializados para favorecer a adaptação a contextos heterogêneos e para integrar experiências vividas. A Teoria das Representações Sociais reconhece "duas classes distintas de universos de pensamento" (Sá, 1993, p. 28) que operam na percepção e na construção da realidade social: o universo reificado e o universo consensual. Enquanto no primeiro, buscam-se "verdades", no segundo, buscam-se "sentidos" (Moscovici, 2007).

O universo reificado corresponde às formas de posicionamento quanto ao conhecimento e às práticas que delimitam aspectos formais da realidade, às verdades definidas por instâncias normalizadoras como as instituições religiosas, as instituições jurídicas e a ciência. Estabelece hierarquias, indicando representantes legítimos do saber, os únicos considerados aptos a falar em seu nome (por exemplo, representantes religiosos, juízes ou médicos). $O$ sujeito que se expressa no registro do universo reificado age, ou tenta agir, como porta-voz autorizado e imparcial de conhecimentos aos quais ele se submete, conhecimentos consagrados por instâncias coletivas, impessoais (Sá, 1993; Moscovici, 2007).

Em contraste, o universo consensual corresponde às formas de posicionamento quanto ao conhecimento e às práticas que delimitam aspectos informais da realidade, aos conhecimentos construídos por pessoas e grupos em sua dinâmica recorrente de interação e comunicação. Essas formas geram conhecimentos "utilitários", representações sociais. O sujeito que se expressa no registro do universo consensual age como "erudito amador", porta-voz de sua própria experiência, veiculando sua visão pessoal em nome de grupos nos quais se insere (Sá, 1993; Moscovici, 2007). O "erudito amador" integra, de forma mais ou 
menos precisa, conhecimentos científicos e outros tipos de saberes institucionalizados a informações adquiridas em sua própria vivência, permeada por pertencimentos grupais e por crenças consagradas pela história e pela cultura. "Tudo o que é dito ou feito ali [nos universos consensuais] apenas confirma as crenças e as interpretações adquiridas, corrobora, mais do que contradiz, a tradição" (Moscovici, 2007, p. 54).

A lógica que rege as representações sociais não é exclusivamente formal, hipotéticodedutiva. As representações integram tipos de raciocínio tradicionalmente atribuídos ao pensamento dito "primitivo" ou pré-formal (animismo, finalismo, realismo, antropomorfismo). A atividade representacional se caracteriza pelo caráter fragmentário e sincrético dos conhecimentos produzidos e pela coexistência, no mesmo grupo ou no mesmo sujeito, de tipos múltiplos e heterogêneos de racionalidade, o que foi chamado de "estado de polifasia cognitiva" (Moscovici, 1961; Jovchelovitch, 2008, 2011).

Neste artigo, dedicado a compreender representações sociais construídas por profissionais de saúde, privilegia-se o que Provencher, Arthi e Wagner (2012) denominaram perspectiva diacrônica para emergência da polifasia cognitiva. Os autores chamam a atenção para a persistência dos conhecimentos ditos "tradicionais" no pensamento "moderno", esse último marcado pelo domínio técnico-científico, e para as profundas e contínuas imbricações entre esses tipos de conhecimentos.

Moscovici (1961) nota que o pensamento de senso comum opera de forma simultânea com sistema e metassistema. O sistema cognitivo, operatório, produz categorizações, associações e diferenciações, mas não funciona sozinho. Ele está inscrito em um metassistema que controla e verifica sua ação, por meio da incidência de normas e valores sociais, de regras que podem ser lógicas ou não (Doise, 2002). Valentim (2013) destaca que a Teoria das Representações Sociais deve ser valorizada como instrumento para analisar a participação desse metassistema na construção das teorias de senso comum, com sua validade e com suas lógicas próprias.

\section{Método}

\section{Participantes}

Participaram desta pesquisa 40 profissionais de Saúde da Família que trabalhavam em 11 diferentes USF localizadas em bairros de classe popular de um mesmo município do sudeste brasileiro, urbano, com população de cerca de 330 mil habitantes. A distribuição dos participantes foi equivalente quanto a gênero (20 homens e 20 mulheres) e quanto à categoria profissional (20 não-médicos e 20 médicos). Essa distribuição é considerada apenas como equalizadora dos participantes da pesquisa quanto às categorias consideradas. Não há intenção aqui de fazer comparações entre esses grupos.

Os participantes tinham idades que variaram de 26 a 61 anos, com média de 36,4 anos $(D P=8,7)$. A média do tempo de profissão foi de 11,1 anos $(D P=8,7)$. A maioria $(67 \%)$ declarou usar bebidas alcoólicas (33\% declararam-se abstinentes) e 52\% afirmaram ter caso de alcoolismo na própria família (pais, irmãos, tios, primos ou cunhados). A maior parte declarou pertencer à classe média (70\%) ou média-alta (22\%).

O projeto foi aprovado por um Comitê de Ética de uma Universidade Federal brasileira. Foram respeitadas todas as diretrizes de ética em pesquisa (Resolução 466/12 do 
Conselho Nacional de Saúde). Os participantes foram entrevistados após terem assinado Termo de Consentimento Livre e Esclarecido.

\section{Instrumentos e procedimentos de coleta de dados}

Os participantes foram abordados em seus locais de trabalho e foram entrevistados individualmente. Um questionário específico foi utilizado para coletar dados sociodemográficos. Foram realizadas entrevistas semiestruturadas com os 40 participantes, com roteiro de entrevista que continha as seguintes questões: 1) Como o alcoolismo aparece na Unidade de Saúde? Como a equipe lida com os casos? 2) Que fatores você destaca como importantes para entender porque alguém se torna alcoolista? e 3) Que tipo de tratamento você acredita que deve ser adotado para pessoas que desenvolveram alcoolismo ${ }^{4} \mathrm{O}$ roteiro abordou, portanto, três tópicos: o fenômeno do alcoolismo nas Unidades, suas causas e seu tratamento.

O número de questões do roteiro foi pequeno, mas o caráter semiestruturado da entrevista permitiu a ampliação e o aprofundamento das respostas. As questões préestabelecidas foram feitas a todos os participantes, mas o pesquisador formulou perguntas e comentários singulares a cada um deles, no intuito de explorar com detalhe aspectos interessantes das falas, promovendo o envolvimento e a expressão dos participantes. 0 pesquisador pediu que experiências vividas pelos profissionais fossem descritas, que expressões e metáforas fossem explicadas. As entrevistas tiveram duração média de 11,4 minutos $(D P=4,7)$.

\section{Método de análise}

As entrevistas foram transcritas integralmente e as respostas dos participantes foram agrupadas em três corpora distintos, relativos aos três tópicos do roteiro de entrevista: o fenômeno do alcoolismo nas USF, causas do alcoolismo e tratamentos preconizados. Esses corpora foram submetidos separadamente à Classificação Hierárquica Descendente por meio do programa ALCESTE v. 4.7 (Analyse des Lexèmes Co-occurants dans les Enoncés Simples d'un Texte - Análise de Lexemas Coocorrentes nos Enunciados Simples de um Texto) proposto por Reinert (2000). Seguindo indicações de Camargo (2005), o vocabulário dos corpora foi padronizado e homogeneizado, para permitir que o ALCESTE considerasse expressões (por exemplo, a expressão "dependente químico" foi grafada dependente_químico) e sinônimos (por exemplo, as expressões "agentes de saúde", "agentes comunitários" e "agentes" foram grafadas agente_de_saúde).

O ALCESTE realiza uma "análise lexicográfica", por meio de testes de qui-quadrado, que indica vocábulos de um discurso que apresentam coocorrência significativa. Mostra os "mundos lexicais" que compõem um discurso e certas relações entre esses mundos (Reinert, 2000; Lima, 2008). Segundo Kronberger e Wagner (2008), “O pressuposto de ALCESTE é que pontos diferentes de referência produzem diferentes maneiras de falar, isto é, o uso de um vocabulário específico é visto como uma fonte para detectar maneiras de pensar sobre um objeto" (p. 427).

\footnotetext{
${ }^{4}$ O roteiro completo contou ainda com a seguinte questão composta, formulada após a primeira: “Você já precisou atender profissionalmente alguém que estava alcoolizado naquele momento? Como foi a experiência? Que sentimentos associa a esse atendimento? ". Os dados gerados por essa questão, analisados alhures, não foram considerados neste artigo.
} 
Inicialmente, o software converte as palavras de cada corpus em formas reduzidas (lematização). Os símbolos "+", "<" e "." são utilizados em diferentes tipos de redução. As palavras "familiar" e "familiares", por exemplo, são consideradas pelo programa como "familiar+" a partir de uma redução da flexão de número. Em seguida, o ALCESTE divide o discurso em trechos de tamanho comparável chamados de "Unidades de Contexto Elementar" (UCE), considerando pausas transcritas, tais como pontuação e parágrafos, e números de "palavras plenas" (Lima, 2008).

Então, o software procede à análise de Classificação Hierárquica Descendente, com a construção de uma matriz com os termos analisáveis como colunas e as UCE como linhas. Com base nas frequências dos termos nas UCE, o algoritmo de análise realiza divisões sequenciais do conjunto de UCE em subgrupos, maximizando a diferença entre eles, o que é verificado por testes de qui-quadrado (Lapalut, 1995; Dransfield, Morrot, Martin \& Ngapo, 2004). A Classificação Hierárquica Descendente implica uma primeira divisão do corpus em dois grandes conjuntos de UCE que compartilham vocabulário o menos possível, que foram denominados "Eixos" neste artigo e que serão retomados mais adiante. Sobre essa primeira divisão, Kronberger e Wagner (2008) afirmam:

O conjunto total de unidades contextuais na matriz de indicadores inicial (unidades contextuais por palavras) constitui a primeira classe. O objetivo do próximo passo é conseguir uma divisão dessa classe em duas, que separem, da maneira mais nítida possível, as classes resultantes, de tal modo que as duas classes contenham diferentes vocabulários e, no caso ideal, não contenham nenhuma palavra sobreposta (p. 429).

As divisões seguem processo iterativo, até que não sejam mais significativas do ponto de vista estatístico, resultando em certo número de classes (subgrupos de UCE). A estabilidade das classes é verificada pela realização de duas análises independentes com base em diferentes tamanhos de UCE. A Classificação Hierárquica Descendente é descrita com mais detalhes por exemplo em Lapalut (1995) e Dransfield et al. (2004).

As UCE (trechos de discurso) são, portanto, agrupadas em "Classes", segundo o critério de diferença máxima entre o vocabulário que as compõem, ou seja, uma Classe é um conjunto de UCE que apresenta vocabulário significativamente diferente de outras Classes. Em seu interior, cada Classe apresenta um conjunto exclusivo de UCE e vocabulário característico, com palavras coocorrentes (De Looze, Roy, Coronini, Reinert \& Jouve, 1999; Reinert, 2000).

Por fim, o ALCESTE exibe gráficos em árvore, chamados dendrogramas, que ilustram a separação entre as Classes. Neste trabalho, foram gerados três dendrogramas, relativos a cada um dos três corpora mencionados. A relação palavra-Classe foi considerada significativa quando o valor de associação da palavra à Classe respectiva foi verificado pelo ALCESTE e quando a palavra ocorreu exclusivamente em certa Classe.

O pesquisador deve interpretar os resultados oferecidos pelo software. Para isso, deve perguntar-se o que significam o agrupamento de certos trechos de discurso em uma Classe, a semelhança interna de vocabulário e a diferença significativa em relação às outras Classes. Parte importante do processo de interpretação é a nomeação das Classes, que indica os tópicos abordados no discurso e seu conteúdo. Para a nomeação de cada uma das Classes geradas pelo ALCESTE, utilizou-se o quadro descrito no Anexo 1.

O ALCESTE mostra certa "topologia" do discurso, ao identificar, por meio das Classes, descrições do mundo com conjuntos estáveis de palavras coocorrentes. Esses conjuntos podem ser chamados de "mundos lexicais", como referência à realidade que eles ajudam a 
produzir. Os mundos lexicais são delimitados uns por oposição aos outros. A proximidade ou distância entre as Classes, evidenciada pelos dendrogramas, permite identificar quais deles são particularmente semelhantes ou particularmente diferentes (Reinert, 2000; Lima, 2008).

Adota-se, neste trabalho, o tipo de interpretação dos resultados obtidos com auxílio do ALCESTE sugerido por Lima (2008). Os falantes ocupam diversos "lugares comuns" de enunciação, aos quais aderem de forma não-consciente. Os lugares comuns são "panos de fundo" cognitivo-discursivo-pragmáticos próprios a um grupo social. Aderir a um lugar comum estimula o recurso a certas combinações lexicais e a práticas discursivas habituais. Essas últimas, por sua vez, indicam elementos cognitivos compartilhados pelo grupo, que são testemunhas de vivências coletivas e que são integrantes de representações sociais. Nas palavras de Lima (2008):

\begin{abstract}
O 'lugar comum' de um grupo ou comunidade releva os hábitos linguísticos e sociocognitivos partilhados por um ou por outro, e, mediante seu estudo, o pesquisador atinge os nódulos culturais das representações sociais: a cognição partilhada, a experiência conjunta marcada por uma prática 'ritualizada' (repetitiva, não necessariamente mística ou religiosa), por sua vez geradora de um léxico próprio, distinguido pela reiteração de certas expressões, combinações lexicais (p. 88).
\end{abstract}

Quando o sujeito fala, ele "habita" certos "lugares mentais" em que se articulam perceptos e afetos conscientes e inconscientes referentes à atividade atual, ao pertencimento a grupos, à memória e às projeções para o futuro. As Classes do ALCESTE são traços desses "lugares" que, em grupos como o que foi investigado, adquirem propriedades "comuns", compartilhadas. No processo de enunciação, o sujeito fala em parte a partir de lugares cognitivo-afetivos-comportamentais produzidos coletivamente, que remetem a sistemas de significação e de experiências compartilhadas. Representações sociais são construídas por processos de comunicação e de interação, organizados e mediados pela linguagem. A análise dos padrões lexicais recorrentes, permitida pelo ALCESTE, revela traços de como elas ganham estabilidade em certo grupo social.

Os lugares comuns, dos quais as Classes geradas pelo ALCESTE são "pistas", correspondem a um ponto de vista ou lugar de pensamento a partir do qual e por meio do qual se produzem sentidos, que podem ser, inclusive, discordantes (Reinert, 2000; Lima, 2008). As Classes não são "categorias puramente semânticas" (Lima, 2008, p. 90), elas são também vestígios da atividade de enunciação, que implica recurso a diferentes pontos de vista. Ao mesmo tempo em que podem ser vistas como "abrigos de sentido", podem ser interpretadas como indicadoras de "lugares comuns", campos representativo-discursivos geradores de sentidos. Esse duplo caráter é importante para sua interpretação e será retomado na discussão.

\title{
Resultados
}

Cada um dos corpora (o fenômeno, as causas, os tratamentos), foi submetido ao ALCESTE de forma independente. Eles apresentaram, respectivamente, 1.147, 638 e 826 linhas de texto. Os dois últimos não cumpriram o critério de cerca de 1.000 linhas como tamanho mínimo para funcionamento ótimo do programa. Entretanto, isso não inviabilizou a análise (Cf. Camargo, 2005). As porcentagens de UCE aproveitadas foram, respectivamente, 69\%, 89\% e 58\%. Segundo Kronberger e Wagner (2008), uma "solução aceitável" (p. 439) requer o mínimo de 70\% de aproveitamento das UCE, o que sinaliza que os resultados relativos ao último corpus têm que ser encarados com reservas. Fez-se aqui a opção de expor, ainda assim, esses resultados, tendo em vista sua correspondência empírica 
e analítica com os resultados relativos aos outros dois corpora, notadamente a mesma lógica de separação em Eixos que será retomada na discussão.

\section{Como o alcoolista aparece}

A análise das respostas relativas à primeira questão, sobre como o alcoolista aparece na Unidade e sobre como a equipe lida com os casos, originou quatro Classes. São descritos, a seguir, alguns termos que caracterizaram essas Classes, retidos segundo o critério de definição desses termos como "presenças significativas" pelo ALCESTE 5 . Para diferenciá-los, no texto, são adotadas duas convenções: marcação por sublinhado e ligação de locuções com hífen. Os sinais "+", "<" e "." referem-se às reduções de termos operadas pelo ALCESTE. Os dendrogramas descritos neste artigo expõem os valores de qui-quadrado de associação de cada termo a cada classe. Por convenção, listam-se 25 termos por Classe, o que é suficiente para ilustrar resultados e análises.

A Figura 1 mostra o dendrograma correspondente às respostas à primeira questão. As porcentagens marcadas sobre a chave se referem ao vocabulário compartilhado entre as Classes (22\% entre Classe 1 e Classes 2/ 3; 68\% entre Classe 2 e Classe 3). Nas Figuras de dendrogramas (Figuras 1, 2 e 3) são indicados certos "Eixos" A e B, relativos à primeira partição do corpus pela Classificação Hierárquica Descendente, que serão retomados na discussão.

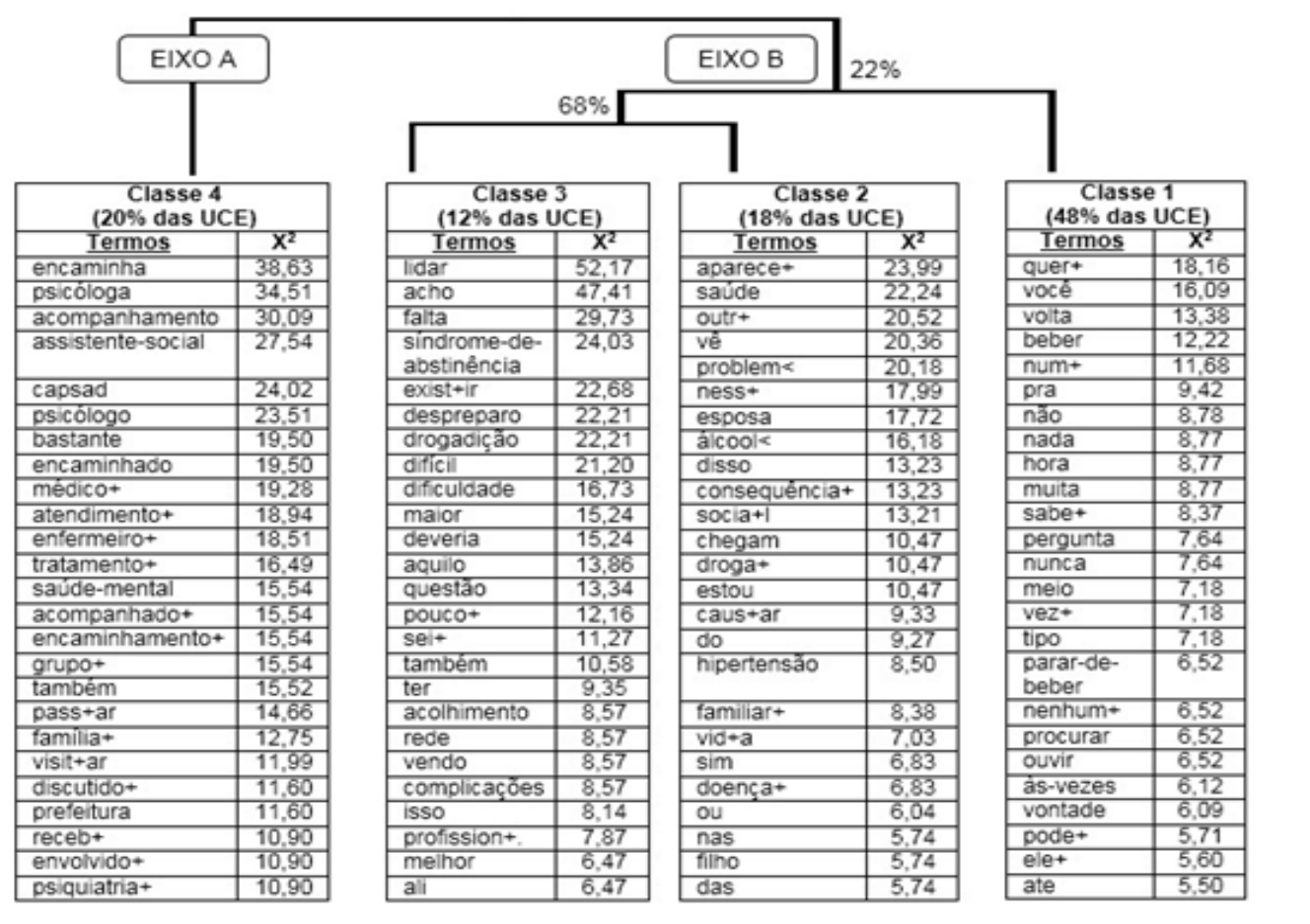

Figura 1 - Dendrograma das Classes geradas pelo ALCESTE a partir das respostas à questão sobre como o alcoolismo aparece e sobre como a equipe lida com os casos (241 UCE), termos característicos das Classes e qui-quadrado $\left(\mathrm{X}^{2}\right)$.

\footnotetext{
${ }^{5}$ Reinert (1986) afirma: "Habituellement, nous relevons tous les vocables associés à un khi2 supérieur à 2.7" (p. 479). (“Normalmente, nós destacamos todos os vocábulos associados a um qui-quadrado superior a 2,7"). Camargo (2005) adota dois critérios simultâneos para retenção de palavras: frequência maior que a média do corpus e "c2 de associação à classe 3,84 (pois o cálculo deste teste estatístico é feito com base em uma tabela com grau de liberdade igual a 1) " (p. 520). Neste artigo, a retenção de palavras foi feita simplesmente com a verificação, por parte do ALCESTE, de que se tratava de "presença significativa". Considera-se que o tipo de análise pretendida permite tal flexibilidade na retenção do vocabulário. Os valores de qui-quadrado são descridos nos dendrogramas.
} 
A palavra mais característica da Classe 1 foi o verbo quer+ (quer, querer), que indica a direção da interpretação adotada: o mundo lexical correspondente se organizou pela noção de vontade, palavra também associada à Classe. Os tópicos evidenciam que se tratava de descrever ações do usuário alcoolista: ele chega bêbado+, quer ou não quer se tratar. Essas ações foram expressas por diversos verbos característicos da Classe: quert, volta, beber, parar-de-beber, ouvir, chegou, etc.

A palavra você designou alternadamente os usuários alcoolistas e os próprios profissionais. Em certos trechos de discurso, fica explícita a oposição entre a (s) vontade (s) (propósitos) desses atores: "vou falar, mas sei que não vai mudar nada", "ele não toma remédio, aí e vai pro bar beber". De um lado, os profissionais prescreviam orientações, acompanhamento contínuo, cumprimento de regras, abstinência e manutenção da vida. De outro, alcoolistas negavam-se a seguir orientações e regras, demandavam atendimentos pontuais, chegavam à Unidade alcoolizados e podiam vir a óbito.

Ao mesmo tempo, o mundo lexical evocou a ideia de impossibilidade: foram numerosas as palavras características da Classe relativas à negação: não, nada, nunca, nenhum, nem, ninguém. Para a pergunta sobre como o alcoolista aparece e sobre como a equipe lida com ele, os profissionais responderam em parte: não é possível, não há lugar, ele não quer. Tendo em vista esse conjunto de tópicos, decidiu-se atribuir o seguinte título à Classe: Vontades contraditórias entre bêbados e profissionais. Destaca-se a presença da palavra bêbado+ não só como adjetivo (ocorrência mais frequente), mas também como substantivo.

No que tange à Classe 2, verifica-se que as palavras outrt, problem< e consequência+ são fundamentais para a interpretação. $\mathrm{O}$ alcoolista aparece na Unidade-de-Saúde, mas aparece por outros problemas. Trata-se de quadros de saúde associados, como indicam, por exemplo, as palavras hipertensão, doença+, ferida, diabete+, intercorrência+; de problemas familiares (esposa, familiar+, filho+) ou problemas sociais ( $\underline{\text { socia }+1}$, rua, população). Falou-se ainda sobre outras drogas.

Certos vocábulos próprios a esse campo lexical evidenciam a associação do alcoolismo a outros problemas: ou, por-exemplo, quando, tanto, junto+. Quanto aos verbos, o discurso dessa Classe enfatizou profissionais que veem, percebem (mesmo quando a demanda direta para tratamento do alcoolismo não é feita) e alcoolistas que aparecem, chegam (principalmente por outros problemas de saúde). A Classe 2 foi intitulada Consequências $e$ outros problemas de saúde, familiares e sociais.

Se a Classe 1 abrigou certa consternação frente às "vontades" do alcoolista, a Classe 3 remeteu a reflexões sobre dificuldades dos próprios profissionais e dos serviços de saúde. As palavras falta, despreparo, difícil e dificuldade são centrais para compreender essa Classe. 0 que estava em questão aqui eram as formas assumidas pelos profissionais para lidar com o fenômeno. A grande maioria dos sentidos produzidos por meio desse mundo lexical se referiu a problemas dos profissionais ou dos serviços de saúde (rede) para fornecer acolhimento e tratar. Isso pode ser ilustrado pelos seguintes trechos de discurso: "não existe, tem que haver uma estruturação melhor dos programas, porque tem os CAPS, mas é uma coisa que deveria ser mais descentralizada e ter uma atenção melhor por parte dos profissionais"; "questão de negligência da SEMUS"; "acho que isso acontece porque falta um pouco mais de entrosamento entre as equipes".

Destacou-se o despreparo para lidar com drogadição, a discriminação e a exclusão. Mas, falou-se também sobre acolhimento e lidar bem, como, por exemplo no trecho: "existe 
uma exclusão, um despreparo, mas existe também um acolhimento". A Classe 3 foi nomeada Formas ambíguas de lidar com alcoolistas: entre acolhimento e exclusão. Notou-se a associação do verbo existir a diferentes dificuldades (exclusão, despreparo, falas preconceituosas). Sua presença sugere que o mundo lexical respectivo foi utilizado para descrever certo status quo. Já a presença do verbo deveria indica a percepção de inadequação do que existe.

A Classe 4, por fim, exibe léxico que ajudou a produzir sentidos particularmente homogêneos, centrando-se na descrição de procedimentos técnicos adotados (eventualmente demandados) frente a casos de alcoolismo. A referência a esses procedimentos foi feita com vários termos característicos da Classe, como encaminha, acompanhamento, encaminhado, atendimento+, tratamento+, acompanhado+, encaminhamento+, grupo+ famíliat, visit+ar, discutido+, receb+er, internação, exame+, referenciat, encaminhar. Falou-se sobre receber, acompanhar, tratar, atender, examinar, internar e encaminhar usuários alcoolistas. Afirmou-se que casos eram discutidos e que famílias eram visitadas ou orientadas.

Em consonância com as múltiplas referências a procedimentos, foram incluídas na Classe várias menções a profissionais e serviços, que muitas vezes caracterizaram os procedimentos: psicóloga, assistente-social, CAPS-ad, psicólogo, médicot, enfermeirot, prefeitura, psiquiatrat, médica<, agente-de-saúde, psicológico, enfermeira. Esses são os atores principais do respectivo mundo lexical, também referidos por meio das expressões agente e equipe. São os principais sujeitos dos verbos mencionados e de outros como faz,

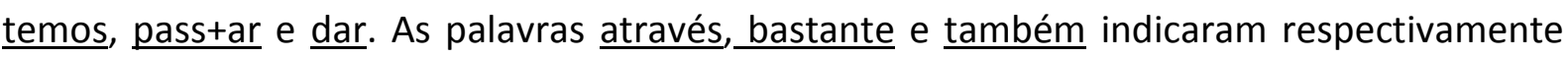
meios para tratar, intensidade de recurso aos meios e simultaneidade de recurso aos meios.

Esses dados expressam contraste marcante com as Classes precedentes, especialmente com a Classe 1. Os tópicos das "vontades" dos alcoolistas, da vinda do alcoolista por causa de outros problemas de saúde e das formas de lidar remeteram hegemonicamente a obstáculos sofridos pelos profissionais, a certa percepção de passividade ou impossibilidade de ação. No mundo lexical correspondente à Classe 4, no entanto, os profissionais foram descritos com posição claramente ativa: eles sabiam o que fazer, podiam fazer muito e faziam muito (no sentido da variedade de alternativas). Considerando os tópicos destacados, a Classe foi nomeada Procedimentos técnicos adotados. Nota-se certa predominância das menções ao encaminhamento, aos profissionais de psicologia e de serviço social e ao CAPS-ad.

A Figura 1 evidencia que a Classe 1 agrupou cerca de 50\% das UCE, sendo, portanto, o "lugar lexical" mais "frequentado" pelos participantes. O contraste descrito entre as Classes 1 e 4 fica graficamente evidente. Elas se encontram em lados opostos do dendrograma. Evidenciam-se duas apreensões contraditórias e simultâneas da realidade social. Por um lado, falou-se sobre motivações e comportamentos dos alcoolistas; por outro, sobre procedimentos técnicos adotados pelos profissionais, suas próprias motivações e comportamentos. De certa forma, esses polos estiveram opostos no pensamento social do grupo. Essa discussão será retomada mais adiante.

Os mundos lexicais aludidos pelas Classes 2 e 3, por sua vez, se mostraram próximos. Poderiam ser agrupados em tópico comum, referente à "dissimulação" do alcoolismo no contexto da Unidade, que era "misturado" a outros quadros (Classe 2) ou excluído (Classe 3). $\mathrm{Na}$ Classe 1, o alcoolismo "assaltava" a Unidade, que "sofria" sua presença. Na Classe 4, ao 
contrário, a Unidade agia sobre ele. Entre os polos passivo e ativo, as Classes 2 e 3 abrigavam certa anulação do fenômeno (ele é excluído, ele é secundário).

\section{As causas do alcoolismo}

As respostas à questão sobre que fatores são importantes para entender porque alguém se torna alcoolista (as "causas" do alcoolismo) gerou três Classes, que aparecem no dendrograma da Figura 2. Os universos lexicais correspondentes às Classes 1 e 3 foram os mais utilizados pelos participantes, com $38 \%$ e $49 \%$ das UCE classificadas. A Classe 2, com $12 \%$ das UCE, mostrou-se particularmente diferente do resto do discurso sobre as causas.

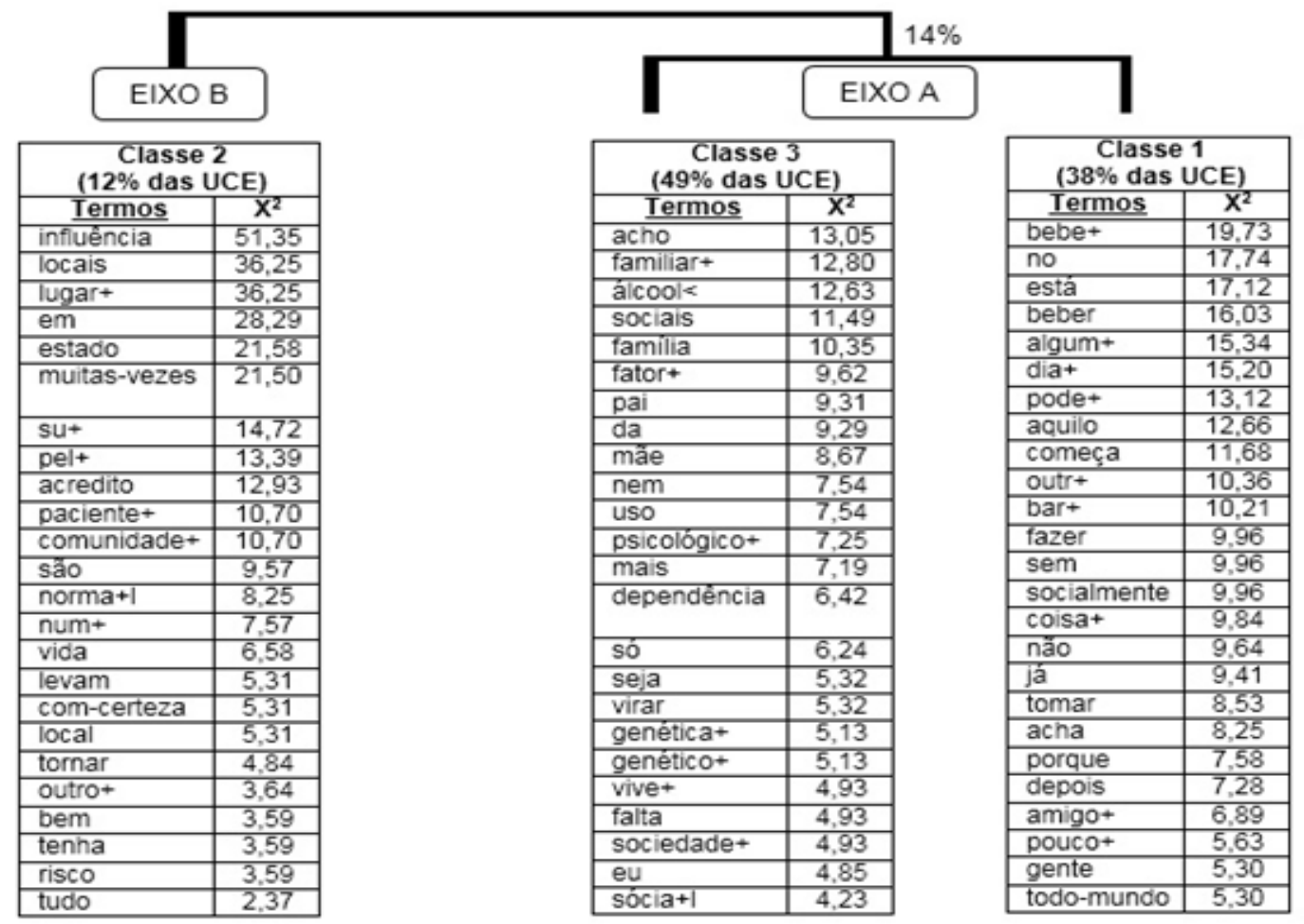

Figura 2 - Dendrograma das Classes geradas pelo ALCESTE a partir das respostas à questão sobre que fatores são importantes para entender porque alguém se torna alcoolista (177 UCE), termos característicos das Classes e qui-quadrado $\left(X^{2}\right)$.

Por meio do contexto lexical próprio à Classe 1, profissionais falaram sobre o beber como ato "normal", aceito socialmente, às vezes incentivado, relacionado aos amigos, ao bar, ao lazer, ao prazer, sendo essas algumas das causas do alcoolismo. Algumas dessas ideias são expressas no trecho: "o grupo inteiro bebe então socialmente, ele passar a beber também pra ser aceito". Relacionam-se a esses tópicos, as palavras: bebe+, beber, bart,

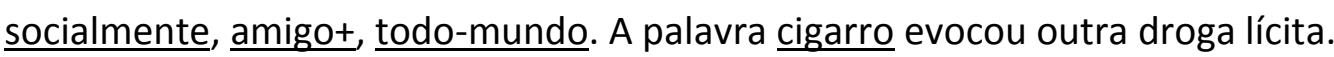

Associaram-se à "alcoolização normal" algumas funções como facilitar a interação social e prover autoafirmação. Fugir de problemas também se apresentou como função da alcoolização, forma de suspender a realidade, de aliviar as dificuldades, as pressões do dia-adia. O verbo começa indica o tópico do início do alcoolismo, caracterizado como insidioso, fazendo fronteira tênue com a normalidade ("começa um dia, começa no outro e depois"). A identificação desses tópicos, todos direta ou indiretamente relacionados à normalidade da alcoolização, levou à nomeação da Classe como Aceitação social do álcool e de suas funções. 
O léxico próprio à Classe 2, por sua vez, foi utilizado para falar sobre a pobreza (isco) dos bairros atendidos pelas USF (comunidade+, locais, lugar) e a sobre a cultura desses bairros, suas condições de vida. É interessante observar que o termo "comunidade" é utilizado no Brasil sobretudo para se referir aos bairros de classe popular. O alcoolismo seria produto da "influência" das comunidades pobres, caracterizada por cultura específica (ao invés de fatores que causam, fala-se de cultura que influencia). A Classe foi nomeada Características e cultura das comunidades pobres. Seguem-se alguns trechos de discurso agrupados nessa Classe: "talvez pela organização daquela comunidade ter reforçado isso"; "A escadaria dá o acesso ao bar, então ela vai ali naquele bar. E a cultura que ela [a pessoa] adquiriu"; "O risco social. Paciente sob risco social, falta de perspectiva de futuro"; "O meio social em que a pessoa vive, eu acredito que tenha forte influência"; "conviver num local como a nossa comunidade aqui, que é uma comunidade de alto risco"; "Muitas vezes as pessoas começam a ingerir bebida_alcoólica pela fome, tem fome, não tem o que comer, uma cachaça por centavos, vai e toma uma cachaça"; "nos locais de morro, nas visitas que a gente faz a gente observa que tem muitos bares".

É interessante observar a associação da palavra cachaça à Classe 2, ao mesmo tempo em que a palavra cerveja se encontrou relacionada à Classe 1. A cachaça parece ligada ao "beber patológico" das comunidades pobres, enquanto a cerveja se associou à alcoolização aceita socialmente. A percepção de que bebidas destiladas estão histórica e culturalmente associadas ao perigo e à pobreza (Sournia, 1986) será retomada na discussão.

Por fim, a Classe 3 agrupou trechos de discurso referentes aos eixos de multicausalidade do alcoolismo: social/ familiar, genético e psicológico. Muitas palavras

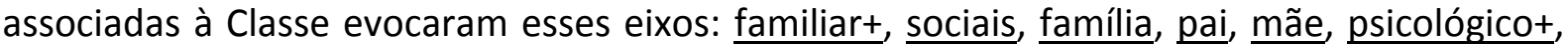
genética+ genéticot, sociedade, sócia+l, psicológica, etc. O recurso a palavras como fatort, dependência, tendência, dependência-química, indica que, nesse mundo lexical, os profissionais buscavam utilizar terminologia técnica. Tratava-se de mencionar e descrever fatores que causavam uma doença, como exemplificam os seguintes trechos: "eu acho que mais fatores sociais. Familiar mesmo"; "predisposição genética de vir a desenvolver a dependência-química"; "psicológicos, sociais e genéticos [...] são os três fatores". A Classe foi nomeada Fatores sociais, genéticos e psicológicos.

A palavra falta sugere que essa apreensão científica do dependente implicava percebêlo como vítima de carências. As palavras mais, principalmente e muito+ foram empregadas para enfatizar fatores sociais e psicológicos.

Para a questão sobre o que causa o alcoolismo, os profissionais responderam, por um lado, que beber é normal e incentivado (convém lembrar que os profissionais, em sua maior parte, declararam ser consumidores de álcool). Associada a essa resposta, encontrou-se a explicação multifatorial aludida na introdução (Souza \& Noto, 2013): beber é "normal" e só se tornam alcoolistas aqueles que sofrem má conjunção de fatores sociais, genéticos e psicológicos. A Classe 2, com léxico particularmente diferente, mostra elemento importante para compreender as representações sociais estudadas: dentre as causas, simultaneamente ao incentivo social e à explicação multifatorial, encontram-se a pobreza e a cultura das "comunidades". 


\section{Os tratamentos que devem ser adotados}

O ALCESTE também foi aplicado ao discurso produzido pelos profissionais para a questão sobre que tratamento deve ser adotado. A Figura 3 mostra o dendrograma gerado a partir das respostas a essa questão sobre o tratamento. Evidenciam-se dois blocos de respostas, com a Classe 1, por um lado e as Classes 2 e 3, que compartilham $48 \%$ do vocabulário, por outro.

\begin{tabular}{|c|c|c|c|c|c|}
\hline \multicolumn{2}{|c|}{$\begin{array}{c}\text { Classe } 3 \\
\text { (25\% das UCE) }\end{array}$} & \multicolumn{2}{|c|}{$\begin{array}{c}\text { Classe } 2 \\
\text { (26\% das UCE) }\end{array}$} & \multicolumn{2}{|c|}{$\begin{array}{c}\text { Classe } 1 \\
\text { (48\% das UCE) }\end{array}$} \\
\hline Termos & $\mathrm{X}^{2}$ & Termos & $\mathrm{X}^{2}$ & Termos & $\mathrm{X}^{2}$ \\
\hline bem & 21,83 & pode+ & 20,14 & acompanhamento & 22,73 \\
\hline onde+ & 17,44 & estar & 13,58 & psicológico & 21,26 \\
\hline melhor+ & 15,32 & interess+ & 8,64 & médico+ & 18,39 \\
\hline situaçāo & 12,15 & vez & 8,64 & multiprofissional & 16,69 \\
\hline volta & 12,15 & talvez & 8,21 & psicólogo & 15,63 \\
\hline ele+ & 11,79 & dificil & 7,83 & assistente-social & 13,95 \\
\hline isso & 10,84 & trabalho+ & 7,83 & psiquiatra+ & 10,43 \\
\hline maneira & 9,03 & ela & 7,82 & caso+ & 6,91 \\
\hline rede & 9,03 & por & 7,82 & só & 6,91 \\
\hline chega & 9,03 & mas & 6,84 & medica< & 6,91 \\
\hline quando & 8,74 & aquel+ & 6,42 & acho & 5,64 \\
\hline faz & 8,31 & pessoa+ & 5,95 & do & 5,62 \\
\hline falei & 8,20 & sei & 5,82 & sócia+1 & 5,59 \\
\hline igual & 8,20 & dizer & 5,33 & dos & 5,59 \\
\hline esta & 6,89 & doença & 5,08 & tratamento+ & 4,95 \\
\hline a-gente & 6,62 & algum+ & 5,01 & cara & 4,43 \\
\hline vocé & 5,90 & aqui & 4,62 & familiar+ & 4,43 \\
\hline vai & 5,75 & mesmo & 3,69 & internação & 4,43 \\
\hline fase+ & 5,67 & nåo & 3,34 & junto & 4,43 \\
\hline sentir. & 5,37 & coisa+ & 3,18 & for & 4,17 \\
\hline encaminhar & 5,37 & profission+ & 3,18 & depender & 3,29 \\
\hline contrarreferência & 5,37 & poderia & 3,07 & passando & 3,29 \\
\hline seria & 3,95 & aquilo & 3,07 & ness+ & 3,29 \\
\hline te & 3,48 & quer+ & 3,07 & $\operatorname{sim}$ & 3,29 \\
\hline
\end{tabular}

Figura 3 - Dendrograma das Classes geradas pelo ALCESTE a partir das respostas à questão sobre que tratamentos devem ser adotados para o alcoolismo (118 UCE), termos característicos das Classes e quiquadrado $\left(\mathrm{X}^{2}\right)$.

A Classe 1 corresponde ao universo lexical que contribuiu para a produção das seguintes ideias: o tratamento deve ser multiprofissional, deve contar com recursos variados e deve incluir a família do alcoolista. Os termos a seguir são exemplos do vocabulário utilizado para veicular essas ideias: psicológico, médico+, multiprofissional, psicólogo, assistente-social, psiquiatra+, medica<, familiar+ internação, família+. A Classe foi nomeada Tratamento multiprofissional do alcoolista e de sua família. Foram agrupados nessa Classe, por exemplo, os trechos: "tem que ter o acompanhamento médico e psicológico"; "na verdade, precisa de uma equipe multiprofissional: tanto de um psicólogo, do assistentesocial, do médico, do enfermeiro"; "grupos de apoio, não só ao alcoolista, mas com a família". Destacou-se ainda a presença de termos que se relacionavam a procedimentos técnicos: acompanhamento, caso, tratamento, internação, clínico, encaminhamento, referência, síndrome-de-abstinência. $\mathrm{O}$ verbo tem evocou a dimensão do desejável ("tem que ter"). 
A Classe 2 inclui outro conjunto lexical do qual os profissionais lançaram mão para falar sobre o tratamento que deve ser adotado. A linha de interpretação que resultou na nomeação da Classe baseou-se na presença de palavras como interess+, quer+, quero, vontade. Falou-se sobre a vontade do usuário e seus suportes, incluindo procedimentos dos profissionais. A Classe foi intitulada Existência da vontade, promoção da vontade.

Os profissionais falaram sobre pessoa que deve ter vontade de se tratar, vontade de parar, de parar-de-beber. Falaram sobre maneiras de promover essa vontade, o que seria feito por profissionais, serviços de saúde ou outros tipos de organização, como indicam as palavras: trabalho+, aqui, profission+, religi<, Alcoólicos-Anônimos. As palavras pode+, talvez, difícil, algum + coisa+, poderia, aquilo mostraram certa indeterminação do que era percebido como necessário para a existência ou a promoção da vontade. É interessante destacar a presença da palavra grupo, que pode ter aparecido como alternativa terapêutica especialmente apta a eliciar interesse pelo tratamento.

Finalmente, a Classe 3 foi interpretada com base na identificação de dois conjuntos de palavras características. De um lado, constaram as palavras a-gente e você, que se referiram aos profissionais das Unidades; de outro, palavras como rede, encaminhar, contrarreferência, CAPS-ad, que remeteram a outros serviços de saúde. Considerou-se que o eixo subjacente ao vocabulário era a ideia de tratamento com recursos próprios versus tratamento com outros recursos. O vocabulário característico e as UCE indicam ênfase no encaminhamento. As ideias de deslocamento do usuário, de tratar ou cá ou lá, foram produzidas com uso das palavras onde+, volta, chega, ir. A Classe recebeu o nome de Encaminhamento e atendimento na Unidade.

\section{Discussão}

O ALCESTE identificou Classes compostas por trechos de discurso (UCE) com vocabulário significativamente semelhante, apresentando listas de palavras e de UCE características. As Classes são indícios de "lugares comuns" (Lima, 2008). Elas não são somente categorias semânticas, mas também marcas da atividade representacional, de lugares comuns, ou seja, de patrimônios sociocognitivos (inserção em grupos, saberes compartilhados, memórias de experiências cotidianas e coletivas, etc.) que foram evocados pelos participantes para falar e por meio dos quais eles construíram sentidos.

Foram destacados dados sobre distância ou proximidade das Classes nos dendrogramas, que correspondem, respectivamente, a diferenças ou semelhanças marcantes entre os mundos lexicais. Para o tipo de interpretação proposto neste artigo, é importante considerar essas diferenças e semelhanças, o que será feito a seguir por meio da abordagem dos Eixos A e B, indicados nas Figuras 1, 2 e 3.

Esses Eixos foram identificados pelo ALCESTE como os conjuntos discursivos caracterizados pelas diferenças mais significativas. A hipótese proposta aqui para explicar essas diferenças é que as falas dos profissionais recorreram simultaneamente a dois sistemas distintos de pensamento e de práticas que organizam a realidade social, o universo reificado e universo consensual (tais como definidos por Moscovici, 2007).

O universo reificado é compreendido com os saberes eruditos ou científicos, com a normatividade das leis e com as hierarquias que eles produzem na ordenação dos papéis sociais (fala-se a partir de um "lugar" autorizado, por exemplo, "como juiz" ou "como médico"). O universo consensual é compreendido com os saberes do cotidiano, com os 
saberes contextualizados, associados à conversação espontânea e aos diferentes tipos de interações grupais (fala-se como "cientista amador", Cf. Moscovici, 1961). Enquanto o Eixo A indica os lugares de enunciação associados ao universo reificado, o Eixo B faz o mesmo para o universo consensual. Sugere-se atentar novamente para as Figuras 1, 2 e 3 para verificar como as Classes apareceram distribuídas nos Eixos.

Os lugares discursivos centrados no universo reificado (Eixo $A$ ) incluíram a imagem do alcoolista que aparece como "usuário normal" (ideal): ele busca o tratamento. As formas de a equipe lidar com os casos são aquelas prescritas pelas ciências e normas da saúde: adotam-se procedimentos técnicos, com várias formas de acolhimento, exame, acompanhamento e encaminhamento (como preconizado, por exemplo, por diretrizes nacionais - Brasil, 2004). As causas do alcoolismo foram informadas pelas ciências genéticofisiológica, psicológica e sociológica: os fatores genéticos, intrapsíquicos, de interação social e a aceitação do álcool como droga lícita (Cf., por exemplo, Souza \& Noto, 2013). O tratamento ganhou contornos ideais: ele deve abarcar a multifatorialidade, deve ser completo, integral, multiprofissional e deve incluir não só o alcoolista, mas também sua família (como preconizado, por exemplo, por Heather \& Stockwell, 2004). Sintetizando, com referência ao universo reificado, o alcoolismo foi representado como doença multifatorial a ser tratada de forma integral.

Ao assumir esses lugares de enunciação, os participantes falaram "como profissionais", informados pelas diretrizes técnico-políticas e pelas ciências da saúde. Expressaram percepções e conceitos sobre as relações formais entre os serviços de saúde, sobre o que deveria acontecer, sobre o que se deveria pensar (sendo provavelmente também aquilo que era percebido como o que se deveria dizer ao pesquisador). Esse registro do discurso buscou minorar a expressão de elementos afetivos.

Enquanto isso, os lugares discursivos centrados no universo consensual incluíram as imagens de como os alcoolistas apareciam mais frequentemente, na percepção dos participantes, no cotidiano das Unidades: pela via das consequências e dos quadros associados e exibindo vontades e condutas inadequadas ou até ameaçadoras. As formas de a equipe lidar com os casos foram descritas eventualmente como acolhimento sem discriminação, mas conferiu-se destaque ao despreparo do profissional e à exclusão do alcoolista (de qualquer maneira, todas essas formas referiam-se a experiências concretas).

A partir desses lugares discursivos, expressou-se a crença de que a gênese do alcoolismo está associada às características e cultura das comunidades pobres. A descrição do tratamento que deve ser adotado se referiu ao domínio da vivência cotidiana: o atendimento possível na Unidade de Saúde e o destaque para o encaminhamento a outros serviços. Nesse ponto, expressou-se também a crença sobre a importância da existência e da promoção da vontade, associada, como visto, às organizações extrassanitárias, religião e Alcoólicos Anônimos. Sintetizando, com referência ao universo consensual, o alcoolismo foi representado como problema social, relacionado à pobreza das comunidades, a ser tratado com os (escassos) recursos disponíveis e com força de vontade.

Ao assumir esses lugares de enunciação, os participantes falaram como "cientistas amadores" (Moscovici, 1961) que consideravam suas vivências cotidianas. Falaram sobre percepções do que acontecia de fato, do que realmente se pensava sobre o fenômeno, o que incluía medidas variáveis do "saber prescrito", e que certamente não se reduzia a ele. Descreveram relações concretas com outros serviços de saúde e integraram mais facilmente expressões de elementos afetivos. 
Representações sociais são frutos de universos consensuais (Moscovici, 2007), ou seja, de situações sociocognitivas em que os sujeitos podem falar não apenas como porta-vozes de um saber consagrado (a ciência, por exemplo), mas sim a partir de seus múltiplos saberes e de suas múltiplas experiências. Ressalta-se que foi esse tipo de situação, a "abertura para a conversação livre", que o pesquisador buscou colocar em marcha com o procedimento das entrevistas semiestruturadas.

Os sujeitos apropriaram-se de conteúdos abstratos e eruditos utilizados nos universos reificados, modificando-os, adaptando-os (Moscovici, 2007; Jovchelovitch, 2011). Vê-se que os participantes produziram representações tendo como base esses dois universos, esses dois aspectos da realidade, esses dois sistemas de pensamento e práticas, ancorando o alcoolismo simultaneamente nas noções de "doença" e de "problema social". As representações articulavam dois discursos em um só.

Como prevê a TRS (Moscovici, 1961, 2007), operava-se uma passagem do não-familiar, as categorias abstratas do universo reificado, ao familiar, os conhecimentos pragmáticos adotados para perceber o objeto e orientar condutas sobre ele no cotidiano. Teorias vivenciais recriavam teorias científicas incorporando-as. Apesar de os profissionais serem legitimados socialmente, por sua formação, como portadores do saber científico, é possível afirmar que seu pensamento sobre os usuários alcoolistas não era pautado unicamente pelas diretrizes e ciências da saúde. Para emitirem suas falas, faziam recurso não só a um sistema cognitivo capaz de conceituar e de operar, mas também a um metassistema sociocognitivo, com características normativas e valorativas (Moscovici, 1961; Doise, 2002).

Sobre a ação desse metassistema nas representações sociais investigadas, é interessante ressaltar a hipótese de que ele integrava julgamentos sobre as classes populares. Os raciocínios empregados fizeram referência a "causas eficientes" (as "causas secundárias" das quais fala Moscovici, 2007), ultrapassando inclusive a causalidade tipicamente biomédica e incluindo fatores psicológicos e sociais, tal como propõe a abordagem técnico-científica atual sobre o alcoolismo (Heather \& Stockwell, 2004; Rotgers \& Davis, 2006). Mas eles também evocaram outra forma de perceber o "fator social" dos casos de alcoolismo, com a associação de palavras como "comunidade", "influência", "cultura", "risco", "bares", "cachaça".

A hipótese de que crenças e julgamentos implícitos sobre a pobreza agiam nos sistemas sociocognitivos investigados é condizente com a constatação de Conrad e Schneider (1992) de que os "desvios", dentre eles o alcoolismo, são atribuídos via de regra aos estratos sociais mais desfavorecidos; esses estratos são percebidos como seu lugar natural.

Sournia (1986) destaca que a massificação do consumo de bebidas alcoólicas na Europa e o grande aumento do uso de destilados, processos que ocorreram do século XVII em diante, foram acompanhados de grande alarme das autoridades quanto aos perigos do álcool. Governantes e especialistas defenderam as crenças de que as únicas bebidas perigosas seriam os destilados, de que o alcoolismo levaria forçosamente ao pecado, à luxúria e às doenças venéreas e de que ele seria essencialmente problema dos pobres.

No século XIX, o alcoolismo foi descrito como causa e efeito da "degenerescência", definida como degradação biológica e moral dos indivíduos que poderia levá-los a deficiências físicas, intelectuais e a diversos tipos de desvio social. Os desvios, por sua vez, poderiam ser transmitidos aos filhos, hipótese que embasou a eugenia. A degenerescência 
era percebida, portanto, como ameaça séria e iminente contra toda a espécie e, particularmente, contra a integridade e o poder do Estado-nação (Sournia, 1986). O que pode ser chamado hoje de ponto de vista moral sobre o alcoolismo guarda crenças e afetos ligados ao tema oitocentista da degenerescência. A ênfase no atentado contra a espécie ou contra a nação foi substituída (e ao mesmo tempo, de certa forma, mantida) pela ênfase na degradação do indivíduo (Sournia, 1986; Ancel \& Gaussot, 1998).

No discurso médico-higienista brasileiro, o alcoolismo também foi tradicionalmente associado à miséria, à precariedade dos bairros pobres e de suas habitações, a seus bares, à cachaça, bebida típica dos "bêbados-pobres" do Brasil. Os bares da "periferia" foram descritos como "antros de degradação", contrapostos ao trabalho e à família (Matos, 2000). Ancel e Gaussot (1998) demonstraram que, para explicar o alcoolismo, o senso comum considera menos as explicações científicas que a imagem concreta da "sarjeta social" do alcoolista. Estudos como o de Matos (2000) mostram que só o homem pobre, o homem das classes populares, pôde ser percebido tradicionalmente como "alcoolista de fato".

Nas análises apresentadas pela presente pesquisa, o jogo entre sistema e metassistema (Doise, 2002) indicou que as representações sociais do alcoolismo construídas pelos profissionais (membros das classes média e média-alta) poderiam estar ancoradas em arraigadas crenças sobre a pobreza e sua suposta degradação moral (Sournia, 1986; Matos, 2000). A Teoria das Representações Sociais mostra-se profícua para a análise das crenças inconscientes que povoam a realidade social e psicossocial.

\section{Considerações finais}

Com a Teoria das Representações Sociais, ressalta-se a validade do conhecimento de senso comum (Jovchelovitch, 2008, 2011; Valentim, 2013): ele permite construir a realidade do fenômeno sobre bases "seguras" (transformar o não-familiar em familiar, Moscovici, 1961, 2007).

Espera-se que esse relato tenha demonstrado a polifasia cognitiva nas representações sociais do alcoolismo estudadas. O público pesquisado é particularmente interessante, pois são credenciados socialmente como legítimos portadores do saber técnico-científico sobre saúde, aqueles que supostamente pautariam apenas nesse saber seu pensamento e atuação. Foi possível constatar que se misturavam aos conhecimentos técnico-científicos, conhecimentos de outras ordens, advindos dos vários domínios do cotidiano e das crenças sócio historicamente bem estabelecidas sobre o alcoolismo e a pobreza. Pode-se inferir que são fontes desses conhecimentos as opiniões veiculadas no cotidiano, as informações da mídia, as imagens das telenovelas e dos filmes e as experiências profissionais e pessoais dos participantes, formações culturais e experiências que se dão no presente e que atualizam crenças tradicionais.

Com os "dois discursos sobre o alcoolismo", alternaram-se e combinaram-se as crenças na onipotência (atividade absoluta do profissional que lida com uma doença multifatorial com um tratamento multidimensionado) e na impotência (passividade absoluta do profissional frente a um problema social, cuja resolução depende de recursos de outros serviços e da vontade dos usuários). Trata-se de ponto particularmente importante para a prática profissional, para a educação permanente e para os demais tipos de intervenção dirigidos aos profissionais: tanto a onipotência quanto a impotência são ilusórias. Não é 
verdade que os profissionais podem tudo frente aos alcoolistas, mas também não é verdade que eles nada podem, como atesta a literatura sobre o tema.

Espera-se também que o relato tenha trazido contribuições para o uso do ALCESTE como metodologia de análise, com o Quadro descrito no Anexo 1, com a análise que integrou a perspectiva pragmatista referida por Lima (2008) e com os conceitos de universo reificado e universo consensual (Moscovici, 1961, 2007).

É interessante relembrar o que afirmou Durkheim (1912/1968) sobre a "oposição absoluta" entre o sagrado e o profano: "Não existe na história do pensamento humano outro exemplo de duas categorias de coisas tão profundamente diferenciadas, tão radicalmente opostas uma a outra" (pp. 43-44, tradução feita pelos autores). Sobre a distinção entre a "esfera sagrada" e a "esfera profana", Moscovici (2007) afirma: "Essa distinção foi agora abandonada. Foi substituída por outra distinção, mais básica, entre universos consensuais e reificados" (p. 49) e afirma que a sociedade, no universo consensual, possui "uma voz humana" e é vista como portadora de sentido e finalidade; enquanto que, no universo reificado, a sociedade é "um sistema de entidades sólidas, básicas, invariáveis" (p. 50) descritas por saberes científicos que estabelecem as verdades a serem impostas às experiências individuais.

Propõe-se aqui que o ALCESTE seja um instrumento particularmente adaptado para identificar, no discurso de certo grupo sobre certo objeto, a presença simultânea desses dois registros, dessas duas visões da sociedade. A Classificação Hierárquica Descendente realizada pelo ALCESTE inclui a divisão inicial dos conjuntos de UCE (trechos de discurso) em dois grandes grupos seguindo o critério de diferença máxima entre o vocabulário, considerado aqui como traço do processo de enunciação. Os dois grandes grupos foram nomeados Eixo A e Eixo B. Propõe-se aqui a hipótese de que essa diferença máxima seja um traço do recurso (inconsciente para o falante, pelo menos em parte) às duas visões de sociedade referidas, aos universos reificado e consensual. É interessante notar que a possível confirmação dessa hipótese reafirma a pertinência do ALCESTE para a análise de representações sociais.

No entanto, é possível que o ALCESTE seja sensível a essa diferença apenas se o corpus submetido à análise tenha a homogeneidade prescrita. Na pesquisa relatada aqui, por exemplo, se todo o discurso dos profissionais sobre fenômeno, causas e tratamento do alcoolismo tivesse composto um único corpus (em vez de três), as Classes obtidas provavelmente não corresponderiam aos Eixos A e B e provavelmente refletiriam as três categorias identificadas de antemão (fenômeno, causas e tratamento).

\section{Referências}

Ancel, P., \& Gaussot, L. (1998). Alcool et alcoolisme. Pratiques et représentations. Paris: I'Harmattan.

Brasil. (2004). A Política do Ministério da Saúde para atenção integral a usuários de álcool e outras drogas. Brasília: Ministério da Saúde.

Camargo, B. V. (2005). ALCESTE: um programa informático de análise quantitativa de dados textuais. In A. S. P. Moreira, B. V. Camargo, J. C. Jesuíno \& S. M. Nóbrega (Orgs.). Perspectivas teórico-metodológicas em representações sociais (pp. 511-539). João Pessoa: UFPB.

Conrad, P., \& Schneider, J. W. (1992). Deviance and medicalization. From badness to sickness. Philadelphia: Temple University. 
De Looze, M. A., Roy, A., Coronini, R., Reinert, M., \& Jouve, O. (1999). Two measures for identifying the perception of risk associated with the introduction of transgenic plants. Scientometrics, 44(3), 401-423.

Doise, W. (2002). Da psicologia social à psicologia societal. Psicologia teoria e pesquisa, 18(1), 27-35.

Dransfield, E., Morrot, G., Martin, J. F., \& Ngapo, T. M. (2004). The application of a text clustering statistical analysis to aid the interpretation of focus group interviews. Food quality and preference, 15, 477-488.

Durkheim, E. (1912/1968). Les formes élémentaires de la vie religieuse (5a ed.). Paris: PUF.

Heather, N., \& Stockwell, T. (2004). The essential handbook of treatment and prevention of alcohol problems. Chichester: John Wiley \& Sons.

Jovchelovitch, S. (2008). Os contextos do saber. Representações, comunidade e cultura. Petrópolis: Vozes.

Jovchelovitch, S. (2011). Representações sociais e polifasia cognitiva: notas sobre a pluralidade e sabedoria da razão em Psicanálise, sua imagem e seu público. In A. M. O. Almeida, M. F. S. Santos \& Z. A. Trindade (Orgs.). Teoria das representações sociais: 50 anos (pp. 159-178). Brasília: Technopolitik.

Kanno, N. P., Bellodi, P. L., \& Tess, B. H. (2012). Profissionais da Estratégia Saúde da Família diante de demandas médico-sociais: dificuldades e estratégias de enfrentamento. Saúde e sociedade, 21(4), 884894.

Kronberger, N., \& Wagner, W. (2008). Palavras-chave em contexto: análise estatística de textos. In M. W. Bauer \& G. Gaskell (Orgs.). Pesquisa qualitativa com texto, imagem e som: um manual prático (7ạ ed., pp. 416441). Petrópolis: Vozes.

Lapalut, S. (1995). Text clustering to support knowledge acquisition from documents. Technical Report no. 2639. INRIA: Le Chesnay.

Lima, L. C. (2008). Programa Alceste, primeira lição: a perspectiva pragmatista e o método estatístico. Revista de educação pública, 17(33), 83-97.

Matos, M. I. S. (2000). Meu lar é o botequim. Alcoolismo e masculinidade. São Paulo: Companhia Editora Nacional.

Moscovici, S. (1961). La psychanalyse, son image et son public. Étude sur la représentation sociale de la psychanalyse. Paris: PUF.

Moscovici, S. (2007). Representações sociais. Investigações em psicologia social. Petrópolis: Vozes.

Provencher, C., Arthi, \& Wagner, W. (2012). Cognitive polyphasia: introductory article. Papers on social representations, 21, 1.1-1.15.

Reinert, M. (1986). Un logiciel d'analyse lexicale. Les cahiers de l'analyse des données, 11(4), 471-481.

Reinert, M. (2000). Les "mondes lexicaux" des six numéros de la revue "Le surréalisme au service de la révolution". Recuperado em 18 outubro, 2011, de http://w3.erc.univ-tlse2.fr/Semin_Reinert_2.html.

Ronzani, T. M., \& Furtado, E. F. (2010). Estigma social sobre o uso de álcool. Jornal brasileiro de psiquiatria, 59(4), 326-332.

Rotgers, F., \& Davis, B. A. (2006). Treating alcohol problems. New Jersey: John Wiley \& Sons.

Sá, C. P. (1993). Representações sociais: o conceito e o estado atual da teoria. In M. J. Spink (Org.). $O$ conhecimento no cotidiano: as representações sociais na perspectiva da psicologia social (pp. 19-45). São Paulo: Brasiliense.

Sournia, J. C. (1986). Histoire de l'alcoolisme. Paris: Flammarion.

Souza, L. G. S. (2012). Profissionais de Saúde da Família e representações sociais do alcoolismo. Tese de doutorado, Universidade Federal do Espírito Santo, Vitória, ES, Brasil.

Souza, I. C. W., \& Noto, A. R. (2013). Abordagens para usuários de álcool. In T. M. Ronzani (Org.). Ações integradas sobre drogas: prevenção, abordagens e políticas públicas (pp. 105-122). Juiz de Fora: Editora da UFJF.

Valentim, J. P. (2013). Que futuro para as representações sociais. Psicologia e saber social, 2(2), 158-166. 
Viana, A. L., \& Dal Poz, M. (1998). A reforma do sistema de saúde no Brasil e o Programa Saúde da Família, Physis revista de saúde coletiva, 8(2), 11-48.

World Health Organization. (2008). The world health report 2008: primary health care now more than ever. Geneva: WHO.

Apresentação: 11/08/2015

Aprovação: 25/11/2015 


\section{Anexo 1}

Quanto à interpretação das Classes, importa considerar ao menos três questões: sobre o que falaram os participantes? Utilizando que vocabulário? Com que tipos de combinações lexicais? Elucidar essas questões revela práticas discursivas recorrentes, que indicam elementos cognitivos compartilhados, integrantes de representações sociais. Revela também a adesão não-consciente dos participantes a "lugares comuns" (Lima, 2008) sóciocognitivo-discursivos.

Importa, primeiro, identificar os tópicos do discurso (sobre o que se falava) e os principais sentidos compartilhados (o que se falava). Para realizar essa tarefa, é preciso considerar o vocabulário de cada Classe e seu uso nas respectivas Unidades de Contexto Elementar (UCE). Recorreu-se então a quadro desenhado especificamente para essa análise, o quadro auxiliar para interpretação de Classes geradas pelo ALCESTE (Quadro AICLA), composto por duas colunas: "Trechos de Unidades de Contexto Elementar" e "Tópicos do mundo lexical".

Esse quadro não pretende ser exaustivo quanto às UCE das Classes. Entretanto, considera os tópicos abordados pela grande maioria delas e é capaz de mostrar que as interpretações têm base empírica consistente. Os Quadros AICLA permitem operar uma espécie de análise de conteúdo cujo corpus se constitui dos conjuntos de UCE isolados pelo ALCESTE para cada Classe. Entretanto, diferentemente da análise de conteúdo, os Quadros não visam principalmente à identificação de conteúdos como opiniões, ideias, crenças, percepções (embora isso também esteja presente), mas sim de tópicos. Busca-se identificar quais foram os assuntos, mais do que quais foram as opiniões.

A palavra tópico tem sentido espacial: um assunto que abriga conteúdos (que podem ser discordantes). Por meio da abstração dos tópicos, chega-se à nomeação da Classe respectiva (assim como na análise de conteúdo, trata-se de articular de forma lógica níveis menores a níveis maiores de abstração). Os nomes das Classes são, portanto, metatópicos que revelam regiões sócio-cognitivo-discursivas mobilizadas para responder às perguntas do pesquisador. Mostra-se a seguir um exemplo, com o Quadro AICLA utilizado para nomear e interpretar a Classe 3 gerada a partir da questão sobre que fatores causam o alcoolismo, intitulada "Fatores sociais, genéticos e psicológicos":

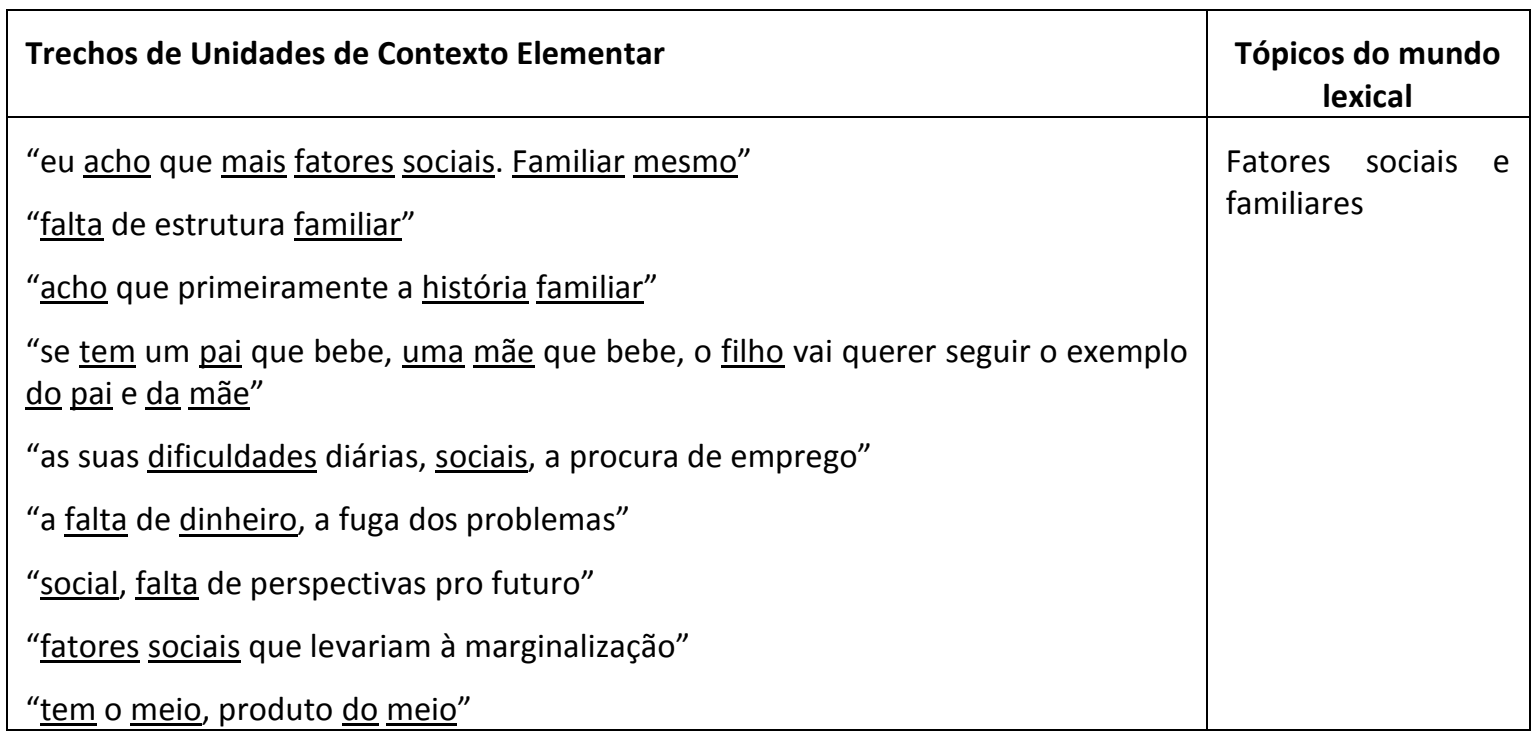




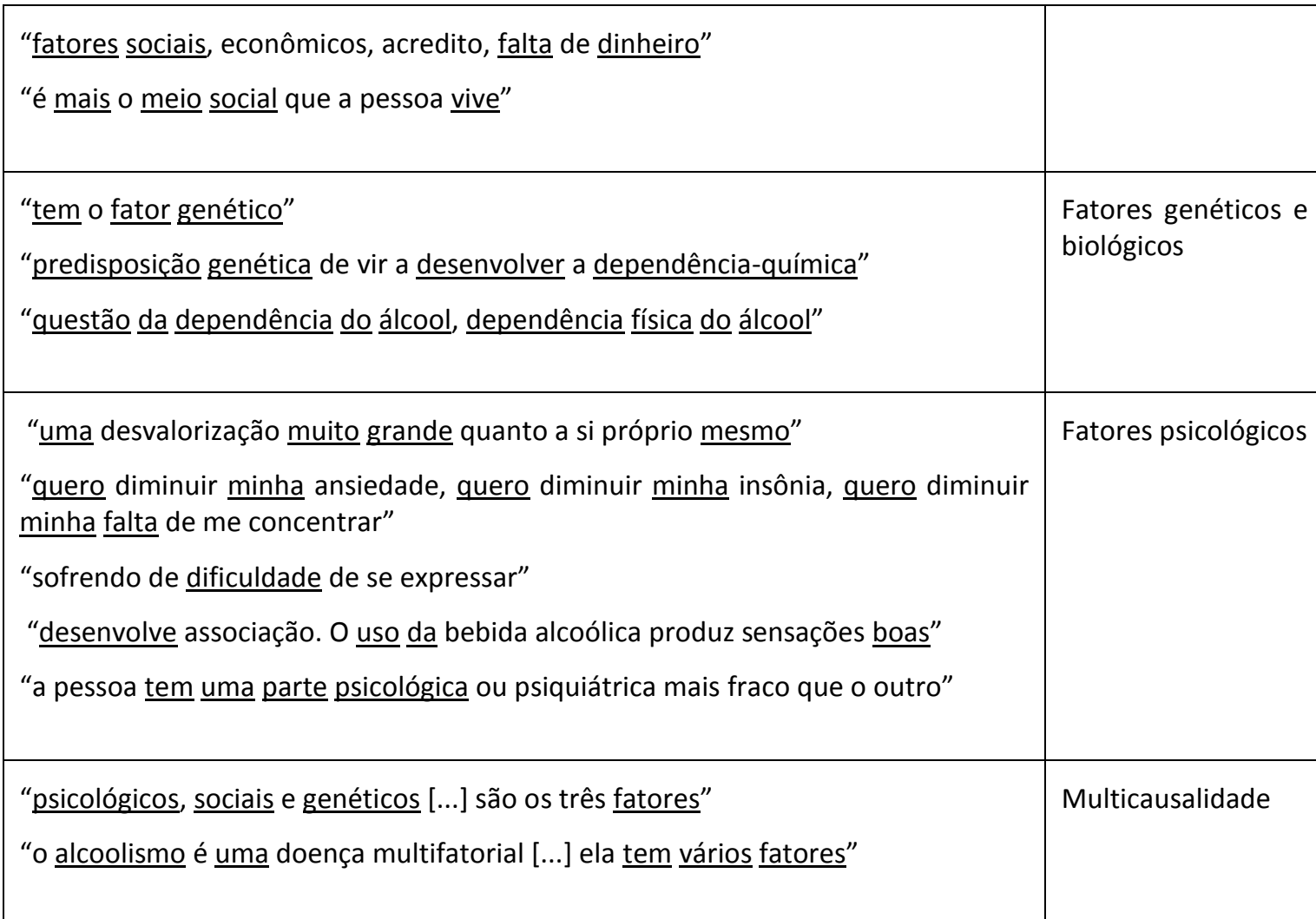

